\title{
Correspondência de Paulo Barreto a João de Barros (I909-I92I): edição crítica e anotada
}

\author{
[ Correspondence from Paulo Barreto to João de Barros (I909-I92I): \\ critical and annotated edition
}

\section{Claudia Poncioni ${ }^{\mathrm{x}}$}

\section{Virginia Camilotti ${ }^{2}$}

RESUMO - O processo de edição das cartas enviadas por Paulo Barreto (João do Rio) ao poeta português João de Barros nas duas primeiras décadas do século XX é analisado neste artigo. Além de situar as circunstâncias e identificar personagens e situações citados, restituindo a comunicabilidade para os leitores de hoje, as autoras refletem sobre as diversas etapas do trabalho de edição e procuram sistematizar as distintas fases do estabelecimento de texto e da anotação desse conjunto de cartas que permite situar tanto as relações culturais entre Brasil e Portugal no período, como as estratégias adotadas pelos dois autores para promoção de suas obras nos dois países. Finalmente, essa correspondência evidencia a extrema ligação entre jornalismo, cultura e política no Brasil e em Portugal, e a existência de uma verdadeira "indústria cultural" entre os dois países naquele período. • PALAVRAS-CHAVE • Epistolografia; Belle Époque; relações culturais e políticas luso-brasileiras; jornalismo; João do Rio; João de Barros. ABSTRACT - This article focuses on the editing process of the letters Paulo Barreto (aka Joao do Rio) sent to Portuguese poet Joao de Barros over the course of the XXth century's first two decades. In addition to reminding us of the circumstances and identifying characters and places it alluded to, depicting with great care that environment to today's readers, the authors reflect on the various editing work related steps and try to clearly identify the multiple chapters associated with the preparation of the text and comments on this group of letters that are today so critical to explain the nature of the relationship between Brazil and Portugal at that point in time, as well as the strategies deployed by each author to promote their works in both countries. In short, that correspondence points at the profound connection between journalism, culture and politics in Brazil, as well as Portugal, and the existence of a true "cultural industry" between the two countries back then. KEYWORDS - Epistolography; Belle Époque; Luso-Brazilian cultural and political relations; journalism; João do Rio; João de Barros.

Recebido em Io de junho de 2017

Aprovado em I3 de agosto de 2017

PONCIONI, Claudia; CAMILOTTI, Virginia. Correspondência de Paulo Barreto a João de Barros (I909I92I): edição crítica e anotada. Revista do Instituto de Estudos Brasileiros, Brasil, n. 67, p. I24-I4I, ago. 2017.

DOI: http://dx.doi.org/Io.II6o6/issn.23I6-90IX.voi67pI24-I4I

I Universidade Paris 3-Sorbonne Nouvelle (Paris, França).

2 Universidade Metodista (Unimep, Piracicaba, SP, Brasil). 
Originada pela falta e pela distância, a correspondência está permanentemente envolvida num processo de compensação e, até mesmo, de recusa de tudo aquilo que separa. Desejo que não visa ignorar, mas sim vencer a distância, pois, mais do que nunca, numa relação epistolar dizer (escrever) é fazer ou, pelo menos, tentar fazer.

Ocorre que, em relação à comunicação literária, a epistolar encontra-se muito mais dependente das circunstâncias, ou seja, dos dados concretos que a regem: momento, lugar, meios de comunicação, identidade das pessoas.

Editar cartas, dar a ler cartas, supõe, destarte, pegar o leitor pela mão para levá-lo até o remetente, fazendo do leitor, de certo modo, um destinatário.

Dentro dessa ótica, a edição da correspondência de Paulo Barreto³ a João de Barros 4 , publicada em 2015 e intitulada Muito d'alma - cartas de Paulo Barreto (João do Rio) a João de Barros - I909-I92I5, que foi realizada no âmbito do projeto "Artífices da correspondência”, liderado por Marcos Antonio de Moraes (IEB/USP) e Claudia Poncioni (Sorbonne Nouvelle), com financiamento do acordo USP/Cofecub, é o objeto deste artigo.

Se o trabalho de edição de correspondências envolve questões que evidenciam, em princípio, a relação entre literatura e história, abrange igualmente questões relativas ao modo de escrever o mundo, de descrevê-lo, na medida em que estamos perante "escritos do real", que compreendem também diferentes estratégias retóricas com finalidades pragmáticas tanto materiais como afetivas.

Nosso trabalho suscitou uma série de reflexões que cremos poder interessar a quem edita cartas. A primeira delas refere-se ao próprio gênero desses textos, que informam em relação tanto à época e às circunstâncias em que foram escritos e lidos

3 João Paulo Emílio Cristovão dos Santos Coelho Barreto (I88I-I92I) utilizou vários nomes de pluma, sendo João do Rio o mais conhecido.

4 João de Barros (I88I-I960).

5 PONCIONI, Claudia; CAMILOTTI, Virginia (Org. e notas). Muito d'alma - cartas de Paulo Barreto (João do Rio) a João de Barros - I909-I92I. Rio de Janeiro: Academia Brasileira de Letras/Garamond, 2015.

6 Referimo-nos aqui à noção desenvolvida por Ivan Jablonka em ensaio epistemológico em que propõe novos caminhos para a historiografia contemporânea. Cf. JABLONKA, Ivan. L'histoire est une littérature contemporaine - manifeste pour les sciences sociales. Paris: Éditions du Seuil, 20I4. 
como à "alma humana", aos sentimentos de amizade, desespero, esperança, raiva, que neste caso, Paulo Barreto compartilhou com João de Barros.

Estamos diante de cartas de escritores. Textos indissociáveis tanto da relação de ambos como de suas respectivas obras nas suas mais diversas variantes (poesia, romance, teatro, crônica e jornalismo). Por ser uma correspondência entre um autor brasileiro e um português insere-se, mais amplamente, no âmbito das relações culturais e políticas entre os dois países. Mas evidencia, também, o circuito comercial e financeiro das relações culturais entre Brasil e Portugal no início do século XX.

O grau de literalidade desses escritos, além de estar patenteado no estilo do destinador, confirma-se por meio de uma evidente ficcionalização, já que, embora assinando apenas duas das 66 cartas como João do Rio, Paulo Barreto constrói um personagem e encena situações onde se produz o homem de teatro.

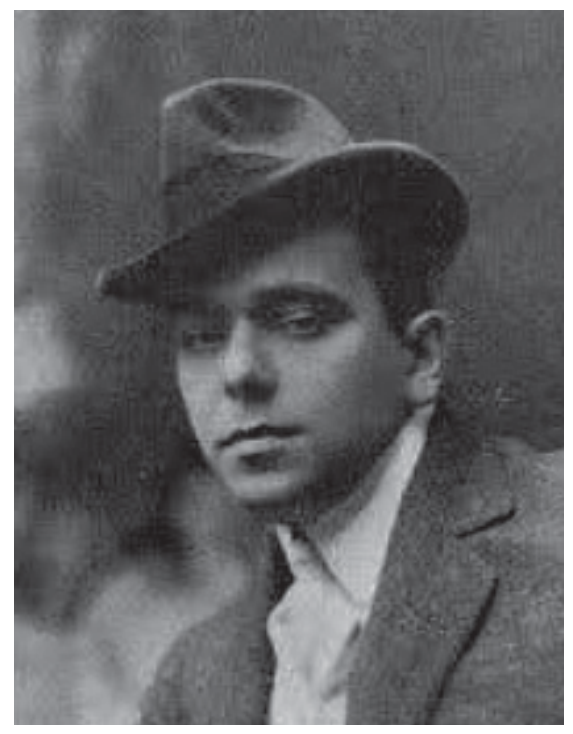

Figura I - Paulo Barreto (João do Rio), I909. Ilustração Portuguesa, Lisboa, 25 de janeiro de I909, p. I25

Localizadas no Arquivo da Cultura Portuguesa Contemporânea da Biblioteca Nacional de Portugal por Claudia Poncioni, em 2005, e numeradas de NII/27I2 a NII/2774, as cartas foram recolhidas, analisadas e anotadas por nós - Claudia Poncioni e Virgínia Camilotti - entre 20II e 20I4. Esse trabalho, que, num primeiro momento, tinha por objetivo a publicação de uma edição anotada, veio a constituir-se numa edição crítica, posto que tais cartas foram publicadas 7 durante o decorrer desse processo, em edição a que tivemos que nos referir.

Vamos tratar, em primeiro lugar, de questões ligadas ao interesse desta

7 D’AVILA, Cristiane (Org.). Cartas de João do Rio a João de Barros e Carlos Malheiro Dias. Rio de Janeiro: Funarte, 2012. 
correspondência que repousa, antes de tudo, nas figuras do destinador e do destinatário, praticamente metonímias do Brasil e do Portugal dos primeiros anos do século XX, ambos antonomásias da figura do "escritor-jornalista-político" e ativos agentes dos negócios culturais luso-brasileiros. Em seguida, exporemos o processo de constituição do corpus do trabalho, apresentando também de modo sucinto os critérios de edição adotados.

Por fim, através de um balanço de nossa experiência, indicaremos algumas possibilidades de leitura e exploração desta edição de correspondência.

\section{DO PECULIAR INTERESSE DESSE CONJUNTO DE CARTAS}

Em I909, quando foi enviada a primeira carta, Paulo Barreto já era um escritor reconhecido e seu principal pseudônimo, “João do Rio", consagrado. Não demoraria muito para assumir a direção do jornal Gazeta de Notícias (I9II).

O livro As religióes no Rio de I904, que a essa altura se encontrava em sua $7^{a}$ edição, tinha sido alvo das penas afinadas de João Ribeiro, Nestor Victor e Elísio de Carvalho, em meio à polêmica discussão quanto à sua natureza - jornalismo ou literatura. Paulo Barreto, apesar de transitar por todos os meios sociais, políticos e frequentar as altas esferas do poder, já tinha visto frustrados seus anseios de conseguir um posto diplomático. Em dezembro de I908, conseguiria finalmente realizar o sonho de conhecer o Velho Mundo. Em Portugal, onde desembarcou e passou mais da metade do tempo de sua estada na Europa, conheceu o jovem poeta João de Barros.

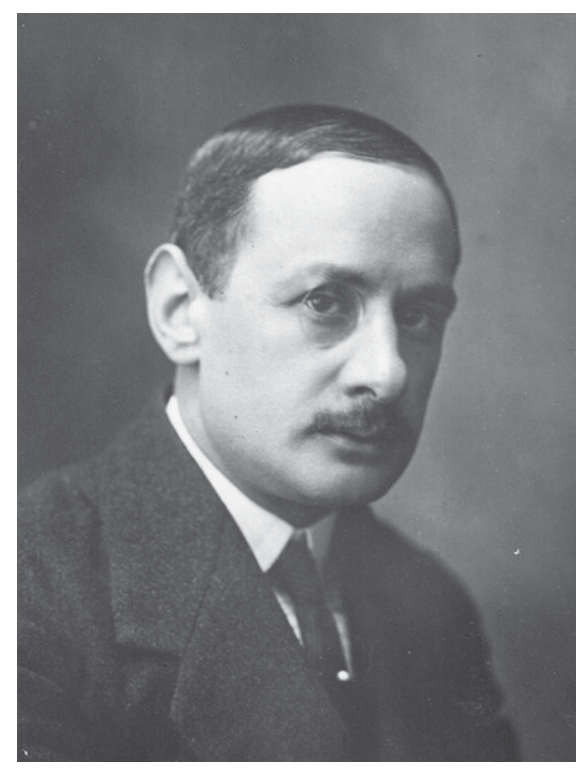

Figura 2 - João de Barros - I9I5. Coleção particular de António de Barros (neto do poeta)

O português já era um autor consagrado em seu país. Embora não fosse membro 
da elite econômica, fazia parte da elite intelectual e militava pela República. Expoente de um grupo de literatos que praticava a denominada "literatura de intuitos", que se assumia como missão ética e social ${ }^{8}$, pretendia subverter mentalidades derivadas do sentimento de decadência nacional, buscando contribuir para a "regeneração da Pátria”. Essa literatura, de corte vitalista e emancipatório, tinha tido na Revista $N v^{\text {Io }}{ }^{\text {IO }}$ e na Revista Arte e Vida ${ }^{\text {II }}$ instrumentos para execução de seu programa.

Com o advento da República em I9Io, João de Barros viria a ocupar cargos muito importantes no seio do Ministério de Instrução Pública, sem, no entanto, renunciar ao seu projeto literário.

Entre I909 e I92I, ano da morte de Paulo Barreto, mantiveram uma relação epistolar assídua e privilegiada. Cabe lembrar que uma das consequências da morte inesperada de Barreto foi a dispersão de seus documentos. Apesar do cuidado de sua mãe em doar a biblioteca e os documentos do filho ao Real Gabinete Português de Leitura do Rio de Janeiro, apenas a biblioteca lá se encontra. Os seus documentos desapareceram, os manuscritos se perderam, e a correspondência passiva dispersou-se. Daí a importância das cartas que enviou a João de Barros.

No Arquivo de Cultura Portuguesa Contemporânea da Biblioteca Nacional de Portugal foi depositado, em setembro de I985, por Henrique Barros, o espólio literário de seu pai.

Na verdade, o depósito feito na Biblioteca Nacional de Lisboa representa apenas parte do acervo, uma vez que outras partes foram assim distribuídas e identificadas: as "cartas políticas", na Casa-Museu João de Deus em Lisboa; manuscritos do autor, de outros, correspondência pessoal e documentos biográficos foram para o Arquivo Histórico Municipal da Figueira da Foz, cidade natal de João de Barros. Uma coleção de fotografias, que registra a presença de João de Barros no Brasil em I9I2, I920, I922, I936, e três cartas de João do Rio, publicadas por Manuela Azevedo em I970 ${ }^{\mathrm{I2}}$, encontram-se ainda em posse dos herdeiros.

Esse ordenamento da correspondência de João de Barros teve como ponto de partida o trabalho pioneiro de Manuela Azevedo, que, ao classificar o conjunto da correspondência em "cartas literárias" e em "cartas políticas”, publicadas em I $982^{13}$, determinou o desmembramento do acervo e sua posterior alocação nas três instituições e a permanência de alguns documentos com a família. Essa classificação,

8 PEREIRA, José Carlos Seabra. L'action littéraire et l'oeuvre poétique de João de Barros. (Thèse pour l'obtention du grade de docteur de troisième cycle). Université de Poitiers. Poitiers, I982, p. 27.

9 Idem. Literatura de intuitos no tempo republicano. Biblos. v. 8-A República e as Letras, 2. série, Coimbra, 20Io, p. 337-4I8, p. 337 .

IO (I9OI-I902).

II (I904-I906).

I2 AZEVEDO, Manuela (Selecção, prefácio e notas). Cartas a João de Barros. Lisboa: Edição Livros do Brasil, s/d, [I970]

I3 Idem (Selecção, prefácio e notas). Cartas políticas a João de Barros. Lisboa: Imprensa Nacional - Casa da Moeda, I982. 
infelizmente, fragmentou um conjunto no qual literatura e política estão, no mais das vezes, profundamente imbricadas.

O corpus que constituímos procurou compensar essa fragmentação e está composto por cartas oriundas dos vários acervos. Reunimos 66 cartas que apresentam uma característica especial - apenas 9 são datadas. O ordenamento cronológico foi a etapa inicial e imprescindível do trabalho de edição. Esse ordenamento pressupôs a identificação de pessoas, obras, manuscritos e colaborações em jornais brasileiros e portugueses citados por Paulo Barreto. A ordem das cartas emergiu através de um constante e rigoroso cotejamento entre os diversos índices temporais, tornado possível graças a trabalhos anteriores de investigação por nós realizados sobre a produção literária e jornalística dos autores e dos contextos culturais e políticos nos dois países.

É de ressaltar que foi um trabalho árduo, pois, muitas vezes, índices encontrados no curso do processo questionaram a ordem cronológica estabelecida, obrigando-nos a estabelecer nova ordem e a refazer o trabalho de anotação.

Ao longo desse processo constatamos progressivamente que o nosso corpus documental não representava o conjunto total da correspondência e que esse corpus era uma fração de uma relação epistolar mais vasta, cujo porte exato não se pode determinar. Há, a título de exemplo, referências presentes em algumas cartas a outras cartas, que não figuram em nenhum dos quatro acervos.

Uma vez organizadas cronologicamente, constatamos um importante desequilíbrio entre o volume de cartas em determinados anos e a escassez ou inexistência absoluta em outros, mais especificamente em I9Io e I9II. Desconhecendo acontecimentos ou discórdias entre ambos que possam explicar tais ausências, concluímos que o conjunto disponível era parcial quer por extravio, quer por vontade dos herdeiros.

Outro aspecto material relevante é que grande parte das cartas foi escrita em papéis timbrados: pessoais, de hotéis, de restaurantes, da revista Atlântida, do jornal A Pátria. Além disso, parte considerável delas foi escrita em "linguados" ${ }^{4}$, redigidas no calor das redações, às pressas, o que explica o estilo, muitas vezes telegráfico. Procuramos respeitá-lo, mantendo a pontuação, a organização dos parágrafos e a organização em itens, assim como as abreviações. Esse trabalho demandou a constituição de uma série de práticas, critérios e códigos relativos tanto à transcrição quanto à anotação.

I4 Laudas manuscritas utilizadas na época nas redações de jornais. 

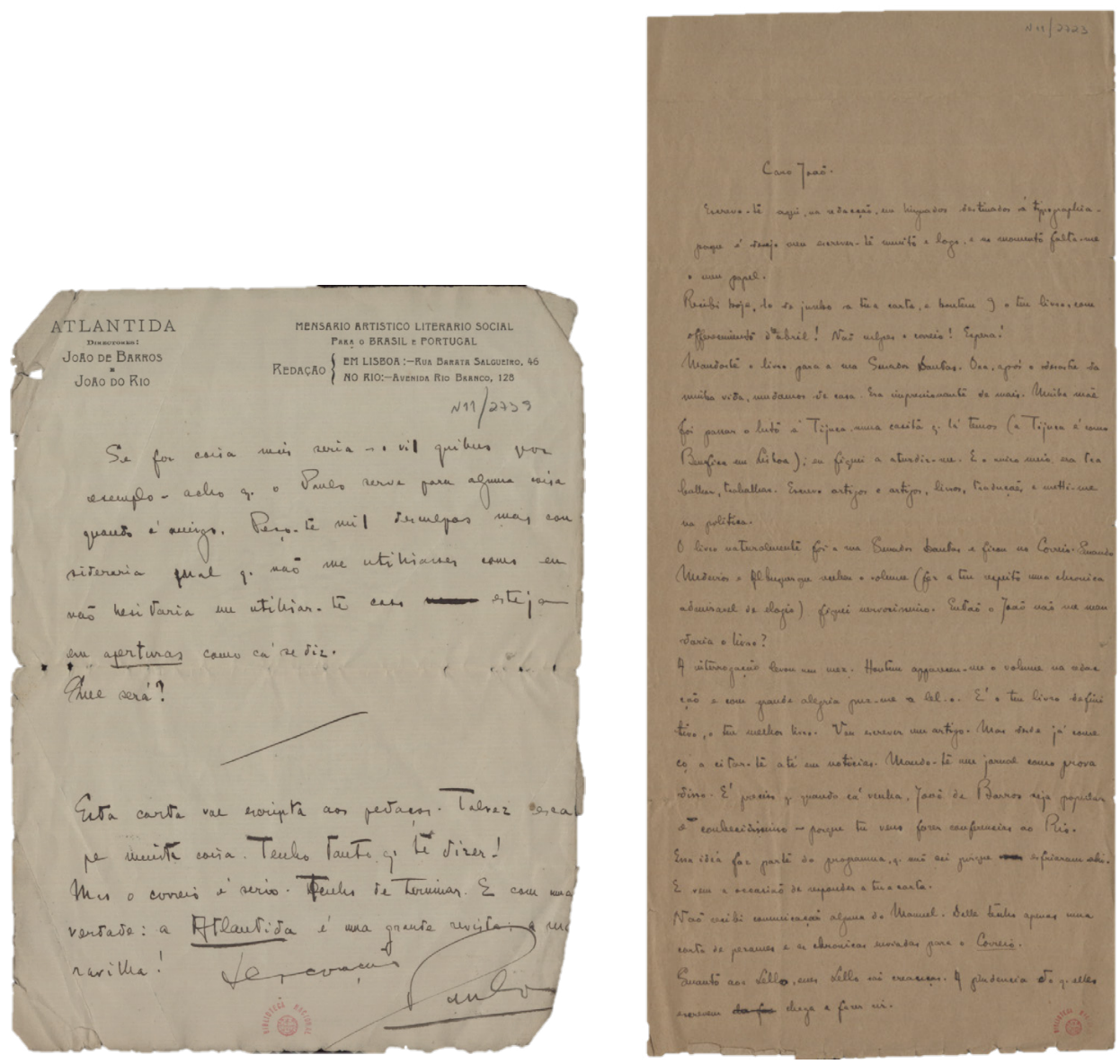

Figura 3-Cartas escritas em linguados

\section{DA RESTITUIÇÃo da COMUNICABILIDADE DA CORRESPONDÊNCIA}

A restituição da comunicabilidade da correspondência é um trabalho que se afilia a uma tradução. O que era inteligível para o destinatário de uma carta torna-se, muitas vezes, de difícil compreensão para um leitor de outra época. Entra, portanto, em cena um intermediário, aquele que edita e anota essa correspondência. Seu papel lembra o do adaptador de uma obra literária ao cinema, na medida em que a mudança de suporte passa por um incontornável trabalho de mediação. Registre-se inclusive que, como numa tradução, a fidelidade ao texto de partida é uma das condições sine qua non da qualidade do trabalho. Porém, a preocupação com a legibilidade pelo leitor de hoje e a conservação de marcas de humor, estados de espírito, alusões exigem sempre reflexão. A reconstituição de situações e circunstâncias evocadas e a identificação de pessoas e eventos inserem-se nesse processo de atualização da legibilidade do texto.

Editar cartas significa lidar com uma pluralidade temporal: o tempo da escrita 
e o tempo da recepção, o tempo da relação entre missivistas, o tempo histórico da correspondência e o tempo presente do leitor. É nessa pluralidade temporal que o editor se inscreve; sua intermediação, que deve levar em conta essa pluralidade, tem o objetivo de significar e de configurar sentido para o leitor. Trata-se de certo modo de uma ambição demiúrgica: a de reconstituir um mundo passado, mas é justamente nesse espaço que reside o instigante trabalho de anotação e de edição de uma correspondência.

A primeira fase do trabalho de edição é o estabelecimento de texto. Questões ligadas à grafia colocam-se logo de início. Decidimos atualizar a ortografia das missivas e, também, os prenomes, mantendo, no entanto, a grafia original dos sobrenomes quando uma nova grafia não havia sido consagrada. Contudo, em casos como o de Wenceslau Braz, grafamos Venceslau Brás, por figurar dessa forma na historiografia republicana.

A abreviação de nomes de instituições requereu inicialmente que as pudéssemos identificar e, em seguida, que mantivéssemos a abreviatura no corpo da carta, sinal da familiaridade dos correspondentes com as instituições referidas, colocando por extenso, em nota, o nome das mesmas. Foi o caso, por exemplo, de A.A. (Agência Americana).

A presença da cultura francesa e da cultura inglesa no Brasil de inícios do século $\mathrm{XX}$ transparece nas cartas através do uso de expressões nos dois idiomas. Se para os correspondentes essas eram utilizadas correntemente, não ocorre o mesmo para o leitor de hoje. Por isso, grafamos em itálico as palavras e expressões estrangeiras, que traduzimos em nota. O mesmo fizemos com expressões em italiano ou em latim, muito mais raras nas cartas, mas que denotam a erudição ou a necessidade de afirmação de um autodidata como era Paulo Barreto.

A ocorrência de rasuras é pouco expressiva nas cartas que editamos, porém são significativas de hesitação ou de uma certa autocensura. Decidimos portanto assinalá-las por meio do formato - [rasura].

Passagens censuradas posteriormente, barradas com tinta ou retiradas através de corte com tesoura, foram assinaladas em nota. Acreditamos que as mesmas decorram da ação de familiares de João de Barros.

Decidimos manter a pontuação (mesmo errática) das cartas, característica do estilo de Paulo Barreto ou ainda da pressa com que foram escritas, salvo quando constatamos que a compreensão das mesmas pudesse ficar comprometida. Apenas nesse caso interviemos na pontuação.

Quando ressaltamos que o trabalho de transcrição passa pela adaptação de um suporte a outro, pensamos em casos em que, no original, algumas frases ou palavras estavam grifadas com o intuito de enfatizar a mensagem que Paulo Barreto procurava transmitir. A questão era complexa, pois havia palavras e frases grifadas uma vez, duas e até três vezes, o que de um ponto de vista tipográfico não era possível reproduzir. A solução encontrada foi sublinhar palavras e frases que originalmente se encontravam com apenas um grifo e sublinhar e grafar também em negrito palavras e frases que apresentam originalmente dois ou mais grifos. 

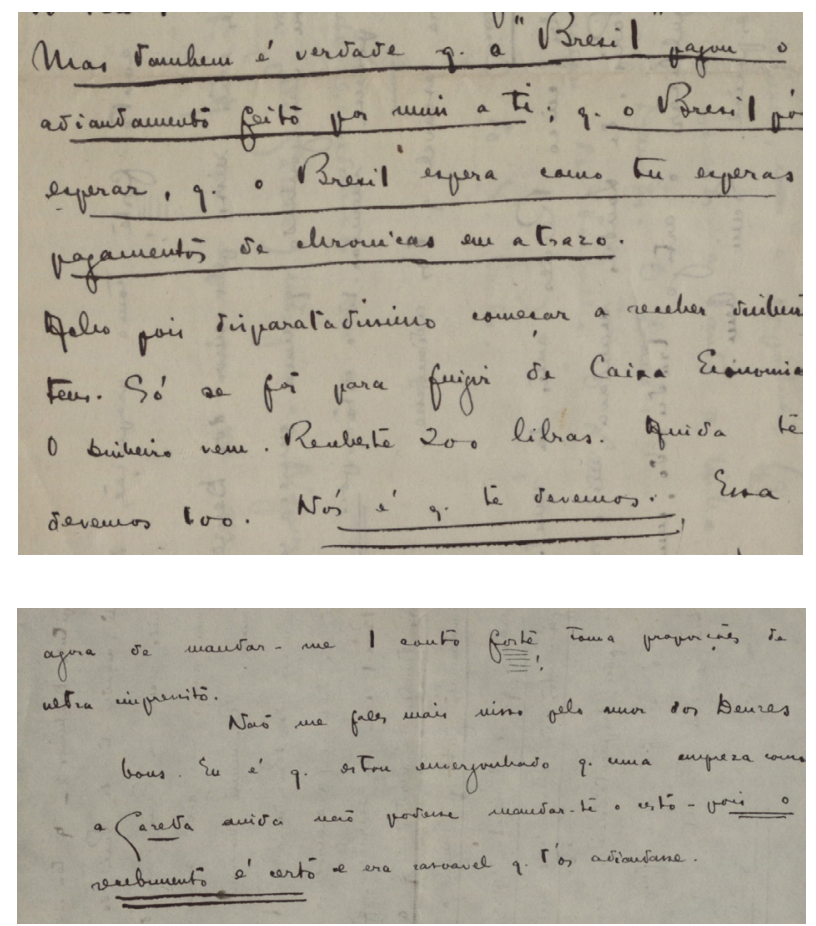

Figura 4-Trechos sublinhados nos manuscritos foram adaptados para destacar a ênfase pretendida pelo autor

Mas também é verdade q. $\mathrm{a}^{22}$ [sic] "Brésil" pagou o adiantamento feito por mim a ti: q. o Brésil pode esperar, q. o Brésil espera como tu esperas pagamentos de crônicas em atraso.

Acho pois disparatadíssimo começar a receber dinheiros teus. Só se for para fingir de Caixa Econômica. O dinheiro vem. Recebeste 200 libras. Ainda te devemos Ioo. Nós é q. te devemos. Essa agora de mandar-me I conto forte toma proporções de ultraimprevisto.

Não me fales mais nisso pelo amor dos Deuses bons. Eu é q. estou envergonhado q. uma empresa como a Gazeta ainda não pudesse mandar-te o resto - pois o recebimento é certo e era razoável q. te os adiantasse.

O emprego sistemático de "q.” por “que”, de “m.” por “meu”, "VV” por "vocês” foi conservado, pois consideramos que imprime um estilo telegráfico às cartas e mostra que, no mais das vezes, foram escritas de um fluxo e sem revisão.

Por outro lado, equívocos ou erros gramaticais (raríssimos) foram mantidos, seguidos de [sic], pois informam sobre as condições de redação, ligadas à urgência em ver partir a carta no navio prestes a zarpar do porto do Rio de Janeiro.

Outra questão que precisamos resolver foi relativa à diagramação das cartas. Como transcrever passagens escritas na perpendicular ou ainda nas margens? Decidimos transcrevê-las no final da carta em questão, assinalando que as mesmas 
foram inseridas num segundo tempo. Deparamo-nos, também, com a questão da organização de temas e projetos em itens. Procuramos respeitar a diagramação adotada pelo destinador, grafando os diversos itens em negrito.

Em sequência, realizamos o trabalho de anotação, para o que foi necessário definir critérios a partir de casos concretos, o que torna difícil uma verdadeira sistematização da prática. Digamos que cada correspondência tem suas próprias exigências. No caso do nosso trabalho, posto que os suportes eram, como já dito, de diverso feitio, começamos por relatar em notas descritivas as características do papel, do timbre ou do cabeçalho.

A identificação de personagens, obras, instituições, situações referidos através de iniciais, apelidos ou alusões, levou-nos à redação de notas explicativas. Políticos, jornalistas, homens de letras foram identificados e relacionados ao contexto da carta.

Os nossos negócios encaminham-se bem. Se for possível, depois do caso de abril, talvez se arranje a tua volta ao Rio, nas férias. Estou com imensa saudade, e o Lauro ${ }^{\text {IIo }}$ e o Enéas $^{\text {III }}$ gostaram muito do teu artigo pedindo ${ }^{\mathrm{Ir} 2}$ a embaixada. ${ }^{\mathrm{Ir}}$

\footnotetext{
по Lauro Severiano Müller (I863-I926). Político e diplomata brasileiro. Em I9I2, Müller foi indicado para o Ministério das Relações Exteriores no governo de Hermes da Fonseca, permanecendo no cargo até 15 de novembro de $1914^{\text {I5 }}$.
}

Quando o personagem voltou a ser referido, inserimos dados que permitiram situar sua atuação naquele preciso momento.

O Cândido tem publicado sempre. E os rapazes q. restam do teu tempo: o Nogueirinha ${ }^{\mathrm{r3}}$ e o Zadir ${ }^{14}$ falam-me q. escreves mais p. S. Paulo.

Com o sítio não se fala de nada senão de sítio. Não fui ainda ao Lauro, ${ }^{15}$ muito balançado pelos amigos do Pinheiro. ${ }^{16}$

\footnotetext{
${ }^{15}$ Lauro Müller. Em I9I4 era ministro das Relações Exteriores do governo de Hermes da Fonseca; continuou no posto (I9I4-I9I7) no governo de Venceslau Brás ${ }^{\mathrm{I} 6}$.
}

A colaboração é q. custa. $\mathrm{O}$ agrado do $2^{\circ}$ número foi maior $\mathrm{q}$. $\mathrm{o} \mathrm{I}^{\circ}$ ainda. Continuas queridíssimo. Quanto à tua viagem - podes estar aqui em junho. Tenho a certeza no ${ }^{2}$ Altino $^{3}$ q. não falha como o raposão Lauro. ${ }^{4}$ É definitivo. Podes vir. Pensando em S. Paulo e no sul.

I5 Carta de classificação NII/2713 na Biblioteca Nacional de Portugal (BNP), escrita em papel timbrado: "Gazeta de Noticias / Rio de Janeiro", [Ano I9I2], p. 72 da edição de Muito d'Alma.

I6 Carta de classificação NII/275I na Biblioteca Nacional de Portugal (BNP), escrita em linguados. [Ano I9I4]; p. 92 da Edição de Muito d'Alma. 
${ }_{4}^{4}$ Lauro Müller. Em I9I6 era ministro das Relações Exteriores do Brasil, no governo de Venceslau Brás ${ }^{\text {T7} .}$

A pesquisa iconográfica que realizamos foi concebida como complementar à identificação e permitiu-nos oferecer ao leitor uma ideia mais precisa dos amigos, aliados mas, também, dos desafetos de Paulo Barreto e João de Barros.

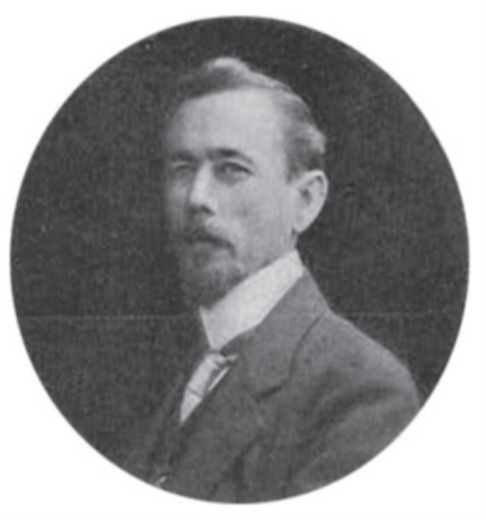

Figura 5 - Lauro Müller. Ilustração Portuguesa, Lisboa, 26 de fevereiro de I9I2, p. 280

Nessas notas de identificação procuramos levar em conta a origem do futuro leitor, português ou brasileiro, veiculando informações que nos pareceram úteis aos dois tipos de leitor. O índice onomástico remissivo, estabelecido de forma exaustiva, permitiu situar o personagem referido nos diversos tempos da relação epistolar.

Outro tipo de notas foram denominadas "conectivas", pois ligadas ao tipo/ natureza da correspondência ou destinadas a abrir perspectivas de leitura que a correspondência implicitamente carrega - rede de intelectuais, a comunicabilidade transatlântica, a dissensão entre homens de letras, a relação Brasil/Portugal, a imbricação entre as esferas da política, da imprensa e das letras. A título de exemplo, podemos citar:

Como vão os teixeiraspaschoaes?94 Os goulartd'andrades\$5 de cá continuam chupando baratas e narcisando-se. Coitados!

\footnotetext{
${ }^{44} \mathrm{~A}$ expressão refere-se à produção literária de Teixeira de Pascoaes (I877-I952), pseudônimo literário de Joaquim Pereira Teixeira de Vasconcelos, que foi escritor e poeta português, principal representante do saudosismo e líder, juntamente com António Sérgio e Raul Proença, do movimento da Renascença Portuguesa. Em I9Io, no Porto, com Leonardo Coimbra e Jaime Cortesão, lançou a revista A Águia, principal órgão do movimento.
}

I7 Carta de classificação NII/2740 na Biblioteca Nacional de Portugal (BNP), escrita em papel timbrado: “João do Rio". [Ano I9I6]; p.I33 da Edição de Muito d'Alma. 
${ }^{95} \mathrm{~A}$ expressão refere-se à produção literária de José Maria Goulart de Andrade (I88I-I936), engenheiro, geógrafo, poeta, romancista e teatrólogo, que desde muito cedo, vinculou-se ao grupo dos poetas boêmios, entre os quais Guimarães Passos, Olavo Bilac, Emílio de Meneses e Martins Fontes. Tornou-se jornalista, sendo um dos redatores de $O$ Imparcial, fundado em I9Io, onde teve convívio com João Ribeiro, Humberto de Campos e Augusto de Lima ${ }^{\mathrm{r}}$.

Ou ainda:

- Os rapazes da Ressurreição ${ }^{\text {100 }}$ devem mandar aos jornais a revista.

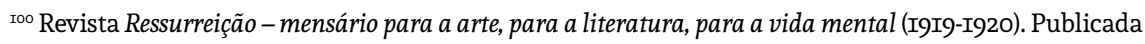
em Lisboa e dirigida por José Gomes Ferreira e Humberto Pelágio (diretor artístico). Nela colaboraram António Nobre, Augusto Gil, Fernando Pessoa, João de Barros e também o desenhista Stuart de Carvalhais. Cf. http://www.iplb.pt/sites/DGLB/Portugues/autores/Paginas/PesquisaAutoresI.aspx? AutorId $=9077$. Consultado em Io de janeiro de $2013^{\text {I. }}$.

Redigimos também notas críticas, relativas às edições anteriores. Estas assumiram dois formatos. Um primeiro, referente a equívocos de estabelecimento de texto em edição anterior:

Não escrevo mais, por falta de tempo. Perderia o Divona. ${ }^{8}$

${ }^{8}$ Divona, navio da Compagnie de Navigation Sud-Atlantique. Em edição da Funarte, 20I2, p. I39, lê-se "divórcio". E a nota 8, p. I4I, esclarece ser mais uma menção de Paulo Barreto ao caso do divórcio do político e escritor, ministro dos Fomentos de Portugal, Brito Camacho ${ }^{20}$.

Um segundo, tocante a equívocos de identificação de personagens, autores, obras, publicações, acontecimentos políticos e sociais:

\author{
Beija o Paulo.55 \\ Beija o Henrique..$^{6}$ \\ O Dantas ${ }^{57}$ falou-me com carinho de ti. \\ Saudades 55
}

I8 Carta de classificação NII/2762 na Biblioteca Nacional de Portugal (BNP) [Ano I9I2]; p. 69 da edição de Muito d'Alma.

I9 Carta de classificação NII/2762 na Biblioteca Nacional de Portugal (BNP) [Ano I9I9]; p.I84 da edição de Muito d'Alma.

20 Carta de classificação N11/2727 na Biblioteca Nacional de Portugal (BNP), escrita em papel timbrado: "João do Rio / 110, A. Gomes Freire / Rio de Janeiro" [Ano 1915]; p. 111 da edição de Muito d'Alma. 


\begin{abstract}
${ }^{57}$ Luiz Martins de Souza Dantas (I876-I954). Diplomata, mais tarde embaixador do Brasil na França. Durante o governo do marechal Pétain salvaria a vida de mais de 475 pessoas, concedendo vistos para o Brasil contra as ordens de Getúlio Vargas. Souza Dantas assumiu interinamente o Ministério das Relações Exteriores em diversas ocasiões durante a gestão Lauro Müller, inclusive em I9I4 por afastamento do ministro. Cf. Relatório do Ministério das Relações Exteriores. Rio de Janeiro: Imprensa Nacional, I93I, p. xxx. Daí a importância dada por Paulo Barreto à simpatia de Dantas com relação a João de Barros. Em edição da Funarte, 20I2, a nota 9, p. 93, identifica Dantas como sendo o escritor português Júlio Dantas ${ }^{21}$.
\end{abstract}

\title{
MAIS ALÉM DAS PÁGINAS...
}

Como já precisamos, torna-se patente à leitura dessa correspondência a relação entre literatura e história. Porém, sendo parte intrínseca da produção de um escritor, sua correspondência guarda uma historicidade específica que, como vimos, é preciso evidenciar sob pena de amputar grande parte de seu significado. Para o caso de Paulo Barreto e João de Barros foi indispensável considerar as complexas relações culturais e políticas entre Brasil e Portugal no início do século XX.

Destarte, a correspondência entre o autor brasileiro e o autor português situa-se, a princípio, numa ambiência de crescente denegação simbólica de Portugal no Brasil, ou, no melhor dos cenários, em meio à disputa, pelo lugar de Portugal nas trocas interculturais com o Brasil

A relação entre Paulo Barreto e João de Barros nasceu durante a primeira viagem do brasileiro à Europa, em dezembro de I908. Ao contrariar o figurino do escritor-viajante da Belle Époque - a peregrinação a Paris -, Paulo Barreto permaneceu em Portugal mais da metade do tempo total da viagem. Foi nessa ocasião que conheceu o jovem poeta João de Barros. Desse encontro surgiu o primeiro projeto comum - uma revista binacional cuja ambição era, a um só tempo, ser veículo de construção de um "destino" comum aos dois países e também o locus privilegiado de sua realização: a revista Atlântida. Projeto esse que somente se concretizaria em I9I5.

Só o desaparecimento súbito de Paulo Barreto (João do Rio) em I92I, em consequência da exaustão física e moral e das intensas pressões políticas e financeiras contra o jornal que fundara - A Pátria, o diário pela "fraternidade latina e aproximação de Brasil e Portugal” -, poria fim a essa relação:

A Pátria é o maior êxito jornalístico do Brasil em todos os tempos. Circulação formidável (maior q. a do Correio da Manhã), autoridade, descomponendas, autora já de duas ou três greves.

Como previa - a campanha contra o jacobinismo chegou a tempo.

2I Carta de classificação NII/2735 na Biblioteca Nacional de Portugal (BNP), escrita em papel timbrado: "João do Rio / 20, Rezende / Telephone 4339 / Rio”. [Ano I9I4]; p. 98 da Edição de Muito d'Alma. 
Tenho neutralizado tudo e estabelecido o desvairo nas hostes desses patetas. Partindo o Afonso Celso ${ }^{22}$ - a pilhéria dos malandros e dos matoides murchará.

Mas esse colossal esforço patriótico traz-me a ruína e a agonia ${ }^{23}$.

Paulo Barreto morreu frustrado com a inviabilidade do maior de todos os projetos que compartilharam - a construção de um ambiente favorável à presença do presidente da República Portuguesa no Centenário da Independência do Brasil, em I922.

Além disso, as cartas de Paulo Barreto revelam as estratégias adotadas dentro dessa disputa, além de testemunharem o trânsito permanente de homens de letras, artistas, editores, impressos de todo tipo (livros, revistas, jornais), nessa conjuntura de crescente animosidade contra Portugal. Tudo isso vem contradizer as teses mais pessimistas sobre a escassez de relações entre os dois países no período.

Nas passagens que se seguem é possível constatar a presença marcante da voz portuguesa nos periódicos da Capital Federal:

Não sei bem da tua vida... no lado prático financeiro. Perdoa a confiança. Não sei se desejas outras crônicas para outros jornais [...] se recebeste do $\underline{\text { Commercio }}^{24}$, da $\underline{\text { Gazeta }}^{25}$, etc.

Acho q. aquelas cartas de Portugal ${ }^{26}$ podem ser [rasuras] feitas quando não tiveres muito q. fazer. [...] O mesmo não digo das crônicas. Mesmo ocupado, o meu egoísmo estético exige q. rutiles na I ${ }^{\mathrm{a}}$ coluna da Gazeta para gozo de todos nós ${ }^{27}$.

Informam também a importante presença física de intelectuais portugueses pelas redações desses mesmos jornais:

Deves ter visto pelas gazetas q. brilhas sem descontinuar nestas paragens. [...] Também, para admirar-te cada vez mais - nada melhor do q. a invasão de pseudointelectuais,

22 Afonso Celso Assis Figueiredo Júnior, conde de Afonso Celso.

23 PONCIONI, Claudia; CAMILOTTI, Virginia, op. cit., p. 229.

24 Commercio de São Paulo.

25 Gazeta de Notícias.

26 Trata-se da colaboração de João de Barros na Gazeta de Notícias.

27 PONCIONI, Claudia; CAMILOTTI, Virginia, op. cit., p. 69. 
q. nos enviam de instante a instante os teus domínios. Imagina q. temos o Homem Christo $^{28}$, o pobre Monteiro ${ }^{29}$ e o António Guimarães ${ }^{30}$.

As cartas denotam ainda o empenho de Paulo Barreto na recepção e acolhida de artistas plásticos portugueses no Rio de Janeiro e em São Paulo - importantes mercados para a produção artística lusitana:

Escrevo-te minutos depois de receber uma carta do António Carneiro ${ }^{31}$. Esse nosso querido artista quer: $I^{\circ}$ - Que o esperem no cais; $2^{\circ}$ - Que lhe arranjem uma pensão (para António e senhora); $3^{\circ}$ - Que já esteja preparado o local da exposição ${ }^{32}$.

Da mesma maneira, as cartas vêm comprovar a presença de peças brasileiras em palcos lisboetas e de portuguesas em território brasileiro, assim como registram o funcionamento das companhias teatrais binacionais, que sintetizam uma arte do espetáculo luso-brasileiro: "Mando-te uma cópia da peça para o República33 e escrevo ao mesmo tempo ao Augusto e ao Visconde. Acho que eles podem montar a peça. É

28 Homem Christo Filho (I892-I928). Intelectual e escritor português. Foi proprietário da Agência Fast de Notícias, com representação no Brasil. Esteve no Brasil, segundo declara no Correio da Manhã de zo de julho de I9I3, como correspondente de jornais franceses para acompanhar a campanha presidencial e fundar a seção franco-brasileira da associação internacional Amitiés franco-étrangères.

29 Fortunato Mário Monteiro de Figueiredo (I885-?). Escritor, jornalista português, diretor proprietário do Jornal d'Alvorada. Após seu envolvimento na fracassada revolução portuguesa de 27 de abril, foge para o Brasil, onde, com Homem Christo Filho, tinha o encargo da propaganda monárquica. Cf. <http:// archive.org/stream/ othalassa0686lisbuoft/othalassao686lisbuoft_djvu.txt>. Acesso em: Io abr. 20I4.

30 António Guimarães (?-?). Autor de As travessuras de Bertha, peça encenada no Rio de Janeiro, no Teatro Trianon. Cf. O País de 6 de junho de I920. PONCIONI, Claudia; CAMILOTTI, Virginia, p. 86.

3I António Teixeira Carneiro Júnior (I872-I930). Poeta, professor e pintor, famoso por seus autorretratos. Fez parte da sociedade Renascença Portuguesa, fundada no Porto em I9II. Dirigiu a revista Águia a partir de I9I2 com Teixeira de Pascoaes. Visitou o Brasil entre I9I4 e I9I5. Nessa ocasião, fez exposição individual na Galeria Jorge, a primeira do gênero no Rio de Janeiro. Cf. UNIVERSIDADE DO PORTO. Antigos estudantes ilustres da Universidade do Porto. Disponível em: 〈http://sigarra.up.pt/up/pt/web_base.gera_pagina?P_pagina=I000929〉. Acesso em: Io jan. 2013.

32 PONCIONI, Claudia; CAMILOTTI, Virginia, op. cit., p. 99.

$33 \mathrm{O}$ atual Teatro Municipal de São Luís em Lisboa. 
universal e com três cenas de levantar a plateia"34. Ou então: "Aí, o Luiz Pereira35 mandou-me pedir por teleg. a Eva ${ }^{36}$. Dei autorização também por teleg." ${ }^{37}$.

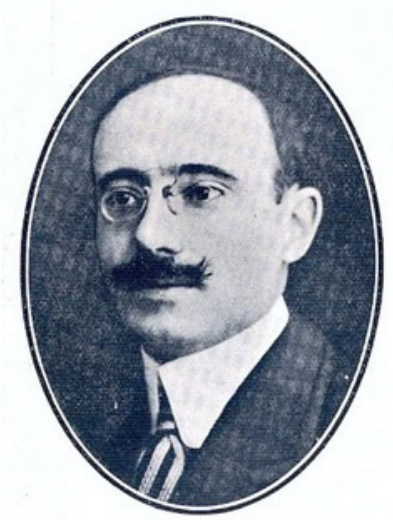

Figura 6 - Augusto de Castro. Coleção particular

Nessa arena de disputa pela presença da figura simbólica de Portugal nas relações interculturais do Brasil, Paulo Barreto teceu uma importante rede de alianças com o meio político nacional em troca da notabilidade que suas notas na imprensa conferiam:

34 PONCIONI, Claudia; CAMILOTTI, Virginia, op. cit., p. 56.

35 Luís António Pereira (?-I938), empresário de teatro português, construtor e diretor do Teatro Politeama de Lisboa.

36 A peça Eva, de autoria de João do Rio, foi representada pela primeira vez no Teatro Casino Antártica de São Paulo, em I3 de julho de I9I5, pela companhia Adelina Abranches. Em Lisboa seria encenada pela primeira vez em abril de I920 no Teatro Politeama e reprisada no Teatro Avenida em dezembro de I922. Cf. <www3.fl.ul.pt/ biblioteca/biblioteca_digital/publicacoes/.../catalogoog.htm >. Acesso em: Io jan. 20I3. Edições portuguesas da peça. Eva - peça em três atos. 2. Ed. Lisboa: Portugal-Brasil, I926

37 PONCIONI, Claudia; CAMILOTTI, Virginia, op. cit., p. 200. 
Deves ter recebido uma carta minha datada de S. Paulo. Se não a recebeste recebê-la-á com esta talvez. Fui lá tratar especialmente do teu caso. O Altino ${ }^{38}$ está muito bem conosco. A gente Rodrigues Alves idem. Falei com o Oscar ${ }^{39}$ e ficou assim combinado: - Virás a S. Paulo, onde farás umas cinco conferências na Escola Normal [...]. O governo retribuirá a tanto cada conferência. Pensei com Oscar I.ooo\$ [...] por cada uma. Assim podes estar aqui junho, ou em julho e agosto ${ }^{4}$.

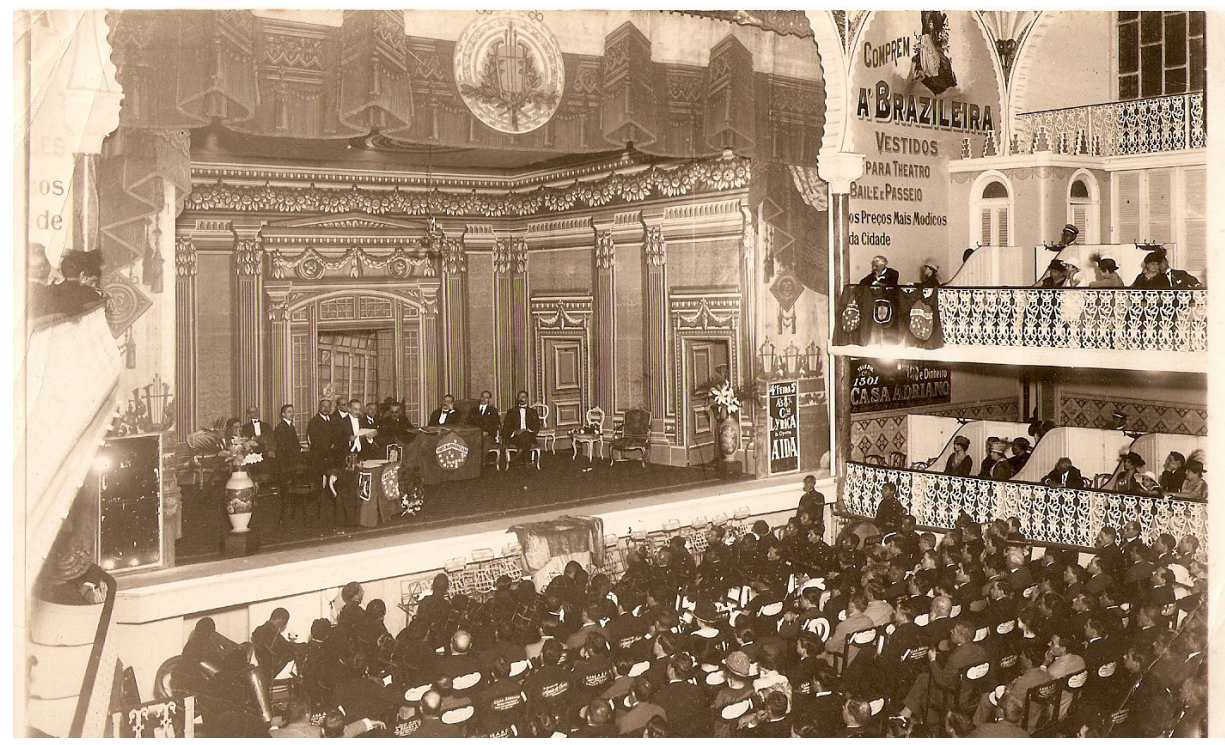

Figura 7-Conferência de João de Barros no Teatro Lírico no Rio de Janeiro durante a segunda estada do poeta no Brasil. Coleção de António de Barros, neto do poeta

Assim, além de responder a um projeto estético e ideológico de aproximação luso-brasileira, do qual a revista Atlântida era emblema, e a uma sincera afinidade eletiva entre os correspondentes, essas cartas inserem-se num conjunto de interesses financeiros relevantes.

38 Altino Arantes Marques (I876-I965). Foi secretário do interior (que englobava Educação e Saúde) de I9I2 a I9I5 no governo do então presidente do Estado de São Paulo Rodrigues Alves. Dois meses depois, em Io de março de I9I6, seria eleito presidente do Estado de São Paulo. Seu mandato vigoraria de Io de maio de I9I6 a Io de maio de 1920 .

39 Oscar Rodrigues Alves (I884-I95I). Foi secretário da Presidência do Estado de São Paulo, de I9I2 a I9I6, no governo de seu pai, Francisco de Paula Rodrigues Alves, e secretário dos Negócios do Interior, de I9I6 a I920, no governo de Altino Arantes. Cf. http://drhu.edunet.sp.gov.br/site_secretario/secretarios/sec_I5.asp >. Acesso em: I2 jan. 2013.

40 PONCIONI, Claudia; CAMILOTTI, Virginia, op. cit., p. I35-I36. 
CLAUDIA PONCIONI é professora titular do

Departamento de Estudos Ibéricos e

Latino-Americanos (Eila) da Université Sorbonne

Nouvelle Paris 3, diretora (Brasil) do Centro de

Pesquisas sobre o Mundo Lusófono (Crepal), autora

de Pontes e ideias: Louis-Léger Vauthier, um engenheiro

fourierista no Brasil (Cepe, 20Io) e coorganizadora, com

Virginia Camilotti, de Muito d'alma - cartas de Paulo

Barreto (João do Rio) a João de Barros - I909-I92I

(Garamond, 20I5).

E-mail: claudiaponcioni@gmail.com

VIRGINIA CAMILOTTI é docente da Universidade Metodista de Piracicaba (Unimep) e do Programa de Pós-Graduação em História (PPGH) da Unesp-Franca, autora de João do Rio: ideias sem lugar (EDUFU, 2008) e coorganizadora, com Márcia Naxara, de Conceitos e linguagens: construções identitárias (Intermeios, 20I3). E-mail: vicamilotti@terra.com.br

\section{REFERÊNCIAS BIBLIOGRÁFICAS}

AZEVEDO, Manuela (Selecção, prefácio e notas). Cartas a João de Barros. Lisboa: Edição Livros do Brasil, $\mathrm{s} / \mathrm{d}$, [I970]

(Selecção, prefácio e notas). Cartas políticas a João de Barros. Lisboa: Imprensa Nacional - Casa da Moeda, I982.

D’AVILA, Cristiane (Org.). Cartas de João do Rio a João de Barros e Carlos Malheiro Dias. Rio de Janeiro: Funarte, 2012.

JABLONKA, Ivan. L'histoire est une littérature contemporaine - manifeste pour les sciences sociales. Paris: Éditions du Seuil, 20I4.

PEREIRA, José Carlos Seabra. L'action littéraire et l'oeuvre poétique de João de Barros. (Thèse pour l'obtention du grade de docteur de troisième cycle). Université de Poitiers. Poitiers, I982.

. Literatura de intuitos no tempo republicano. Biblos. v. 8 - A República e as Letras. 2. série, Coimbra, 20Io, p. 337-4I8.

PONCIONI, Claudia; CAMILOTTI, Virginia (Org. e notas). Muito d'alma - cartas de Paulo Barreto (João do Rio) a João de Barros - I909-I92I. Rio de Janeiro: Academia Brasileira de Letras: Garamond, 20I5. UNIVERSIDADE DO PORTO. Antigos estudantes ilustres da Universidade do Porto. Disponível em: <http:// sigarra.up.pt/up/pt/web_base.gera_pagina?P_pagina=I000929>. Acesso em: Io jan. 2013. 